\section{DOES SEX INFLUENCE PREVALENCE OF PARASITIC INFECTION AMONG CAPTIVE WILD MAMMALS? AN OBSERVATION AT THE ZOOLOGICAL GARDEN, THIRUVANANTHAPURAM, KERALA}

\author{
A. Varadharajan ${ }^{1}$, V. Ramesh ${ }^{2}$ and C. Pythal ${ }^{3}$ \\ ${ }^{1}$ 1/73E, Super Complex, P.G. Palayam, Salem, Tamil Nadu 639119, \\ India. \\ ${ }^{2}$ Ph.D Scholar, Department. of LPM, Madras Veterinary College, \\ Chennai, Tamil Nadu 600007, India. \\ ${ }^{3}$ College of Veterinary and Animal Sciences, Mannuthy, Thrissur, \\ Kerala 680651, India.
}

Zoological gardens play a vital role in the preservation of wild animals for aeshetic, educational and conservation purposes. They also serve as a sole breeding foci for certain highly endangered species. Parasitic diseases constitute one of the major problems causing even mortality in wild animals in captivity (Rao \& Acharjyo, 1984). Although there have been numerous studies on the prevalence of gastro interstinal parasitism in wild animals, there have been only a limited number of parasite surveys conducted for the influence of sex among them.

The present investigation was undertaken to find out the influence of sex on the prevalence of parasitic infection in different zoo mammals at the Thiruvananthapuram Zoological Garden.
One hundred and eight fresh faecal samples ( 52 from males and 56 from females) were collected from the wild mammals kept in individual enclosures and mixed species exhibits. The collected samples were immediately preserved in two per cent potassium dichromate and five per cent formaldehyde. Then the samples were processed with concentration methods of centrifugationcum-sedimentaion technique and examined for parasitic infections. The results are presented in Table 1.

Of the 52 samples from males and 56 samples from females examined, 40 samples (76.92\%) and 39 samples (69.64\%) respectively were found positive for parasitic infections. The common parasites identified in herbivores were strongyle, amphistome, Strongyloides and Fasciola; in carnivores Ancylostoma, Toxascaris, Diphyllobothrium and Paragonimus; and in omnivores, strongyle, Strongyloides and Hymenolepsis. (Varadharajan \& Pythal, 1999). Of the 33 males and 39 females examined among herbivoroes, 25 (75\%) and 26 (66.66\%) respectively were found positive for parasitic infection. Male animals of Spotted Deer, Sambar and Black Buck had higher prevalence rate than the females. But in Hog Deer the females had higher prevalence rate. Among omnivores 13 males and 11 females examined, $11(84.61 \%)$ and eight $(72.72 \%)$ were positive respectively. In the case of carnivores six males and six females examined, four $(66.66 \%)$ and five $(83.33 \%)$ were positive respectively. In Lion, females had higher prevalence of infection than males.

\section{References}

Rao, A.T. and L.N. Acharjyo (1984). Diagnosis and classification of common diseases of captive animals at Nandankanan Zoo in Orissa (India). Indian J. Anim. Hlth. Dec.: 147-152.

Varadharajan, A. and C. Pythal (1999). Parasites of wildlife - I. A preliminary investigation on the parasites of wild animals at the Zoological Garden, Thiruvananthapuram, Kerala, Zoos' Print J. 1-14 (3-12): 159-164. 
Table 1. Influence of sex on the prevalence of parasitic infection among zoo animals

\begin{tabular}{|c|c|c|c|c|c|c|c|c|}
\hline \multirow[t]{2}{*}{ Hosts } & \multicolumn{2}{|c|}{$\begin{array}{l}\text { No. of animals } \\
\text { at the Zoo* }\end{array}$} & \multicolumn{3}{|c|}{$\begin{array}{l}\text { No. of samples } \\
\text { collected from }\end{array}$} & \multicolumn{3}{|c|}{$\begin{array}{l}\text { No. positive for parasitic } \\
\text { infections }\end{array}$} \\
\hline & Male & Female & Male & Female & Total & Male & Female & Total \\
\hline \multicolumn{9}{|l|}{ Herbivores } \\
\hline 1. Spotted Deer Axis axis & 16 & 29 & 9 & 14 & 23 & $8(88.88)^{\star}$ & *10(71.43) & 18(78.26) \\
\hline 2. Sambar Cervus unicolor & 13 & 21 & 6 & 10 & 16 & $5(83.33)$ & $7(70)$ & 12(75.00) \\
\hline 3. Hog-Deer Axis porcinus & 7 & 10 & 5 & 7 & 12 & $2(40)$ & $3(42.85)$ & $5(41.66)$ \\
\hline 4. Blackbuck Antilope cerivcapra & 9 & 4 & 6 & 3 & 9 & $5(83.33)$ & $2(66.66)$ & $7(77.77)$ \\
\hline 5. Barking Deer Muntiacus muntjak & 3 & 1 & 1 & 1 & 2 & $1(100)$ & $1(100)$ & $2(100)$ \\
\hline 6. Nilgai Boselaphus tragocamelus & 3 & 2 & 2 & 1 & 3 & - & - & - \\
\hline 7. Cape baffalo Syncerus caffer & 1 & 1 & 1 & 1 & 2 & $1(100)$ & $1(100)$ & $2(100)$ \\
\hline 8. Mithun Bos sondaicus & 2 & 2 & 1 & 1 & 2 & $1(100)$ & $1(100)$ & $2(100)$ \\
\hline 9. Hippo Hippopotamus amphibius & 2 & 2 & 1 & 1 & 2 & $1(100)$ & $1(100)$ & $2(100)$ \\
\hline Total & & & 32 & 39 & 71 & $25(75.75)$ & $26(66.66)$ & $51(70.83)$ \\
\hline \multicolumn{9}{|l|}{ Omnivores } \\
\hline 10. Wild Boar Sus scrofa & 11 & 8 & 9 & 6 & 15 & $9(100)$ & $9(100)$ & $15(100)$ \\
\hline 11. Rhesus Macaque Macaca mulata & 1 & 1 & 1 & 1 & 2 & - & - & - \\
\hline 12. Bonnet Macaque Macaca radiata & 4 & 5 & 1 & 2 & 3 & - & - & - \\
\hline 13. Sloth Bear Melursus ursinus & 1 & 1 & 1 & 1 & 2 & $1(100)$ & $1(100)$ & $2(100)$ \\
\hline 14. Toddy Cat Paradoxurus hermaphroditus & 1 & 1 & 1 & 1 & 2 & $1(100)$ & $1(100)$ & $2(100)$ \\
\hline Total & & & 13 & 11 & 26 & $11(84.61)$ & $8(72.72)$ & 19(73.07) \\
\hline \multicolumn{9}{|l|}{ Carnivores } \\
\hline 15. Jackal Canis aureus & 4 & 2 & 2 & 1 & 3 & $2(100)$ & $1(100)$ & $3(100)$ \\
\hline 16. Tiger Panthera tigris & 2 & 3 & 1 & 1 & 2 & $1(100)$ & $1(100)$ & $2(100)$ \\
\hline 17. Lion Panthera leo & 4 & 11 & 2 & 3 & 5 & - & $2(66.66)$ & $2(40.00)$ \\
\hline 18. Leopard Panthera pardus & 1 & 1 & 1 & 1 & 2 & $1(100)$ & $1(100)$ & $2(100)$ \\
\hline Total & & & 6 & 6 & 12 & $4(66.66)$ & $5(83.33)$ & $9(75.00)$ \\
\hline Grand Total & 85 & 105 & 51 & 56 & 107 & $40(76.92)$ & $39(69.64)$ & 79(73.14) \\
\hline
\end{tabular}

* Exclusing younger animals ** Figures in paranthesis indicates percentages. 